\title{
Fixed Point Theorems for Multivalued Nonself $G$-Almost Contractions in Banach Spaces Endowed with Graphs
}

\author{
J. Tiammee, ${ }^{1}$ P. Charoensawan, ${ }^{2}$ and S. Suantai ${ }^{2}$ \\ ${ }^{1}$ Department of Mathematics and Statistics, Faculty of Science and Technology Thailand, Chiang Mai Rajabhat University, \\ Chiang Mai 50300, Thailand \\ ${ }^{2}$ Department of Mathematics, Faculty of Science, Chiang Mai University, Chiang Mai 50200, Thailand
}

Correspondence should be addressed to S. Suantai; suthep.s@cmu.ac.th

Received 2 September 2016; Revised 7 November 2016; Accepted 27 December 2016; Published 31 January 2017

Academic Editor: Nawab Hussain

Copyright (C) 2017 J. Tiammee et al. This is an open access article distributed under the Creative Commons Attribution License, which permits unrestricted use, distribution, and reproduction in any medium, provided the original work is properly cited.

In this paper, we prove some fixed point theorems for multivalued nonself $G$-almost contractions in Banach spaces with a directed graph and give some examples to illustrate our main results. The main results in this paper extend and generalize many known results in the literature therein.

\section{Introduction}

Fixed point theory plays a very important role in nonlinear analysis, economics, and applications. The important tool for solving existence problems in many branches of mathematics and applied sciences is Banach contraction principle [1]. It has been generalized in many directions by many authors ([215]).

On the other hand, the fixed point theory for nonself mappings has been studied by many authors ([3-5]). In 2013, Berinde and Păcurar [5] introduced the new type of contraction for nonself single valued mappings.

Definition 1 . Let $K$ be a nonempty subset of a normed space $X$. A mapping $T: K \rightarrow X$ is said to be almost contractive if there exist $\delta \in[0,1)$ and $L \geq 0$ such that

$$
\|T x-T y\| \leq \delta\|x-y\|+L\|y-T x\|
$$

for all $x, y \in K$

By the above definition, they proved some fixed point theorem for almost contractive mappings in Banach spaces.

Later, Alghamdi et al. [4] extended the almost contractive mappings to a multivalued nonself almost contractions.

Definition 2. Let $(X, d)$ be a complete convex metric space and $K$ a nonempty subset of $X$. A mapping $T: K \rightarrow C B(X)$ is said to be a multivalued almost contraction if there exist $\delta \epsilon$ $[0,1)$ and $L \geq 0$ such that

$$
H(T x, T y) \leq \delta d(x, y)+L d(y, T x)
$$

for all $x, y \in K$, where $H(\cdot, \cdot)$ is the Pompeiu-Hausdorff metric induced by $d$.

They proved a fixed point theorem for multivalued nonself almost contraction on convex metric spaces.

Let $G=(V(G), E(G))$ be a directed graph, where $V(G)$ is a set of vertices of graph and $E(G)$ is a set of its edges. Assume that $G$ has no parallel edges. We denote by $G^{-1}$ the directed graph obtained from $G$ by reversing the direction of edges: that is,

$$
E\left(G^{-1}\right)=\{(x, y):(y, x) \in E(G)\} .
$$

Let $x$ and $y$ be two vertices in $G$; a path in $G$ from $x$ to $y$ of length $n \in \mathbb{N} \cup\{0\}$ is a sequence $\left\{x_{i}\right\}_{i=0}^{n}$ of $n+1$ vertices such that $x_{0}=x, x_{n}=y,\left(x_{i-1}, x_{i}\right) \in E(G)$ for each $i=1,2, \ldots, n$. A graph $G$ is said to be connected if there exists a (directed) path between any two vertices of $G$. We denote

$[x]_{G}^{N}=\{y \in X:$

there is a path in $G$ of length $N$ from $x$ to $y$. 
On the other hand, in 2008, Jachymski [6] extended Banach contraction principle by introducing the notion of $G$-contraction and proved a fixed point theorem for $G$ contractions in a metric space endowed with a directed graph. These results have been generalized by some authors in several ways (see [7-14]).

Motivated by the previous results, we introduced the concept of multivalued nonself $G$-almost contractions in normed spaces and establish some fixed point theorems for this this type of mappings in normed spaces endowed with a directed graph. We give some examples to illustrate our main results.

\section{Preliminaries}

In this section, we give some basic and useful definitions and known results that are useful for the main results in this paper.

Let $X$ be a normed space. We denote by $\mathrm{CB}(X)$ the class of all nonempty closed and bounded subsets of $X$. For any $A, B \in \mathrm{CB}(X)$, define the function $H: \mathrm{CB}(X) \times \mathrm{CB}(X) \rightarrow \mathbb{R}^{+}$ by

$$
H(A, B)=\max \{\delta(A, B), \delta(B, A)\}
$$

where

$$
\begin{aligned}
& \delta(A, B)=\sup \{d(a, B): a \in A\}, \\
& \delta(B, A)=\sup \{d(b, A): b \in B\}, \\
& d(a, C)=\inf \{\|a-x\|: x \in C\} .
\end{aligned}
$$

Note that $H$ is called the Pompeiu-Hausdorff metric induced by metric $d$.

The following lemma is very useful for our main results.

Lemma 3 (see [2]). Let $(X, d)$ be a metric space. If $A, B \in$ $\mathrm{CB}(X)$ and $a \in A$, then, for each $\epsilon>0$, there exists $b \in B$ such that $d(a, b) \leq H(A, B)+\epsilon$.

Let $X$ be a normed space, $K$ a nonempty closed subset of $X$, and $T: K \rightarrow C B(X)$ a nonself mapping. If $x \in K$ with $T x \subset K$, then we can always choose an $y \in \partial K$ such that $y=(1-\lambda) x+\lambda z$, where $0<\lambda<1$ and $z \in T x \backslash K$, which expresses the fact that

$$
\|x-z\|=\|x-y\|+\|y-z\|
$$

We denote

$$
\begin{aligned}
& P_{T}(x)=\{y \in \partial K:\|x-z\|=\|x-y\| \\
& +\|y-z\| \text { where } z \in T x\} .
\end{aligned}
$$

The following property was introduced by Jachymski [6]. It is very useful for our main results.

Property $A$ (see [7]). With any sequence $\left(x_{n}\right)$ in $X$, if $x_{n} \rightarrow x$ and $\left(x_{n}, x_{n+1}\right) \in E(G)$ for all $n \in \mathbb{N}$, then $\left(x_{n}, x\right) \in E(G)$ for any $n \in \mathbb{N}$.

In order to obtain our main results, we need the following definition of domination in graphs $[16,17]$.
Let $G=(V(G), E(G))$ be a directed graph. A set $X \subseteq V(G)$ is called a dominating set if, for all $v \in V(G) \backslash X$, there exists $x \in X$ such that $(x, v) \in E(G)$ and we say that $x$ dominates $v$ or $v$ is dominated by $x$. For any $v \in V$, a set $X \subseteq V$ is dominated by $v$ if $(v, x) \in E(G)$ for any $x \in X$ and we say that $X$ dominates $v$ if $(x, v) \in E(G)$ for all $x \in X$.

\section{Main Results}

In this section, we prove some fixed point theorems for multivalued nonself $G$-almost contractions in a Banach space endowed with a directed graph. First, we recall some definitions which are useful for our main results.

Definition 4. Let $K$ be a nonempty subset of a normed space $X$ and $G=(V(G), E(G))$ be a directed graph such that $V(G)=K$. A mapping $T: K \rightarrow \mathrm{CB}(X)$ is said to be $G$-almost contraction

(1) if there exist $\delta \in(0,1)$ and $L \geq 0$ with $\delta(1+L)<1$ such that, for any $x, y \in K$,

$$
H(T x, T y) \leq \delta\|x-y\|+L\|y-T x\|
$$

whenever $(x, y) \in E(G)$,

(2) if $u \in T x$ and $v \in T y$ are such that $d(u, v) \leq d(x, y)$; then $(u, v) \in E(G)$.

First, we prove a fixed point theorem for a $G$-almost contraction in a Banach space endowed with a directed graph.

Theorem 5. Let $K$ be a nonempty closed subset of a Banach space $X$ and $G=(V(G), E(G))$ be a directed graph such that $V(G)=K$. Let $T: K \rightarrow C B(X)$ be a G-almost contraction. Suppose that

(1) T satisfies Rothe's boundary condition: that is, $x \in$ $\partial K \Rightarrow T x \subset K$,

(2) K has Property A,

(3) there is $x_{0} \in X$ such that $\left(x_{0}, y\right) \in E(G)$ for some $y \in$ $T x_{0}$

(4) $P_{T}(x)$ is dominated by $x$ for all $x \in C$ with $T x \notin K$.

Then $T$ has a fixed point in $K$.

Proof. Let $x_{0} \in K$ be such that $\left(x_{0}, y_{1}\right) \in E(G)$, where $y_{1} \in$ $T x_{0}$. If $y_{1} \in K$, we denote $x_{1}=y_{1}$ : that is, $\left(x_{0}, x_{1}\right) \in E(G)$. If $y_{1} \notin K$, there exists $x_{1} \in \partial K$ such that

$$
\left\|x_{0}-x_{1}\right\|+\left\|x_{1}+y_{1}\right\|=\left\|x_{0}-y_{1}\right\|
$$

Since $P_{T}\left(x_{0}\right)$ is dominated by $x_{0}$, we obtain $\left(x_{0}, x_{1}\right) \in E(G)$. If $x_{0}=x_{1}$ then $x_{0} \in T x_{0}$. Suppose $x_{0} \neq x_{1}$; we can choose $k_{0} \in \mathbb{N}$ such that

$$
\delta^{k_{0}}<(1-\delta)\left\|x_{0}-x_{1}\right\| .
$$


By Lemma 3, we can choose $y_{2} \in T x_{1}$ such that

$$
\begin{aligned}
\left\|y_{1}-y_{2}\right\| & \leq H\left(T x_{0}, T x_{1}\right)+\delta^{k_{0}} \\
& \leq \delta\left\|x_{0}-x_{1}\right\|+\operatorname{Ld}\left(x_{1}, T x_{0}\right)+\delta^{k_{0}} \\
& =\delta\left\|x_{0}-x_{1}\right\|+\delta^{k_{0}}<\left\|x_{0}-x_{1}\right\| .
\end{aligned}
$$

Hence, $\left(y_{1}, y_{2}\right) \in E(G)$. If $y_{2} \in K$, we denote $x_{2}=y_{2}$. If $y_{2} \notin K$, then there exists $x_{2} \in \partial K$ such that

$$
\left\|x_{1}-x_{2}\right\|+\left\|x_{2}-y_{2}\right\|=\left\|x_{1}-y_{2}\right\| \text {. }
$$

If $x_{1}=x_{2}$ then $x_{1} \in T x_{1}$. Suppose $x_{1} \neq x_{2}$; we can choose $k_{1} \in \mathbb{N}$ with $k_{1}>k_{0}$ such that

$$
\delta^{k_{1}}<(1-\delta)\left\|x_{1}-x_{2}\right\| .
$$

By Lemma 3, we can choose $y_{3} \in T x_{2}$ such that

$$
\begin{aligned}
\left\|y_{2}-y_{3}\right\| & \leq H\left(T x_{1}, T x_{2}\right)+\delta^{k_{1}} \\
& \leq \delta\left\|x_{1}-x_{2}\right\|+\operatorname{Ld}\left(x_{2}, T x_{2}\right)+\delta^{k_{1}} \\
& =\delta\left\|x_{1}-x_{2}\right\|+\delta^{k_{1}}<\left\|x_{1}-x_{2}\right\| .
\end{aligned}
$$

Hence, $\left(y_{1}, y_{2}\right) \in E(G)$. By induction, we obtain two sequences $\left\{x_{n}\right\}$ and $\left\{y_{n}\right\}$ such that

(i) $y_{n+1} \in T x_{n}$;

(ii) $\left\|y_{n}-y_{n+1}\right\| \leq H\left(T x_{n-1}, T x_{n}\right)+\delta^{k_{n}}$, where

(a) $y_{n}=x_{n}$ if $y_{n} \in K$,

(b) $y_{n} \neq x_{n}$ whenever $y_{n} \notin K$, and then $x_{n} \in \partial K$ is such that

$$
\left\|x_{n-1}-x_{n}\right\|+\left\|x_{n}-y_{n}\right\|=\left\|x_{n-1}-y_{n}\right\|
$$

(c) $\left\{k_{n}\right\}$ is a sequence of positive integers with $\delta^{k_{n}}<$ $(1-\delta)\left\|x_{n}-x_{n+1}\right\|$.

Suppose that

$$
\begin{aligned}
& P=\left\{x_{k} \in\left\{x_{n}\right\}: x_{k}=y_{k}\right\}, \\
& Q=\left\{x_{k} \in\left\{x_{n}\right\}: x_{k} \neq y_{k}\right\} .
\end{aligned}
$$

Note that $\left\{y_{n}\right\} \subset K$ and $\left(y_{n}, y_{n+1}\right) \in E(G)$ for all $n \in \mathbb{N}$. Moreover, if $x_{k} \in Q$, then both $x_{k-1}$ and $x_{k}$ belong to the set $P$. Since $x_{k-1}$ and $x_{k}$ are not in the set $Q$ for all $k$, we cannot have two consecutive terms of $\left\{x_{k}\right\}$ in the set $Q$.

Now, we claim that $\left\{x_{n}\right\}$ is a Cauchy sequence. We conclude that there are three possibilities.

Case 1. If $x_{n}, x_{n+1} \in P$, then $x_{n} \in T x_{n-1}$ and $x_{n+1} \in T x_{n}$. Since $T$ is a $G$-almost contraction and $\left(x_{n}, x_{n+1}\right) \in E(G)$, we have

$$
\begin{aligned}
\left\|x_{n}-x_{n+1}\right\| & =H\left(T x_{n-1}-T x_{n}\right)+\delta^{k_{n-1}} \\
& \leq \delta\left\|x_{n-1}-x_{n}\right\|+L d\left(x_{n}, T x_{n-1}\right)+\delta^{k_{n-1}} \\
& =\delta\left\|x_{n-1}-x_{n}\right\|+\delta^{k_{n-1}} .
\end{aligned}
$$

Case 2. If $x_{n} \in P$ and $x_{n+1} \in Q$, then $x_{n} \in T x_{n-1}$ and $y_{n+1} \neq$ $x_{n+1}$ : that is,

$$
\left\|x_{n}-x_{n+1}\right\|+\left\|x_{n+1}-T x_{n}\right\|=\left\|x_{n}-T x_{n}\right\| .
$$

Since $T$ is a $G$-almost contraction and $\left(x_{n}, x_{n+1}\right) \in E(G)$, we have

$$
\begin{aligned}
\left\|x_{n}-x_{n+1}\right\| & \leq\left\|x_{n}-x_{n+1}\right\|+\left\|x_{n+1}-y_{n+1}\right\| \\
& =\left\|x_{n}-y_{n+1}\right\|=\left\|y_{n}-y_{n+1}\right\| \\
& \leq H\left(T x_{n-1}-T x_{n}\right)+\delta^{k_{n-1}} \\
& \leq \delta\left\|x_{n-1}-x_{n}\right\|+L d\left(x_{n}, T x_{n-1}\right)+\delta^{k_{n-1}} \\
& =\delta\left\|x_{n-1}-x_{n}\right\|+\delta^{k_{n-1}} .
\end{aligned}
$$

Case 3. If $x_{n} \in Q$ and $x_{n+1} \in P$, then $x_{n-1} \in P$ and $y_{n} \neq x_{n}$ such that

$$
\left\|x_{n-1}-x_{n}\right\|+\left\|x_{n}-T x_{n-1}\right\|=\left\|x_{n-1}-T x_{n-1}\right\| .
$$

Moreover, $y_{n-1}=x_{n-1}$ and $y_{n} \in T x_{n-1}$. Since $T$ is a $G$-almost contraction, we have

$$
\begin{aligned}
& \left\|x_{n}-x_{n+1}\right\|=\left\|x_{n}-x_{n+1}\right\| \leq\left\|x_{n}-y_{n}\right\|+\left\|y_{n}, y_{n+1}\right\| \\
& \leq\left\|x_{n}-y_{n}\right\|+H\left(T x_{n-1}-T x_{n}\right)+\delta^{k_{n-1}} \\
& \leq\left\|x_{n}-y_{n}\right\|+\delta\left\|x_{n-1}-x_{n}\right\| \\
& +\operatorname{Ld}\left(x_{n}, T x_{n-1}\right)+\delta^{k_{n-1}} \\
& \leq\left\|x_{n}-y_{n}\right\|+\left\|x_{n-1}-x_{n}\right\| \\
& +\operatorname{Ld}\left(x_{n}, T x_{n-1}\right)+\delta^{k_{n-1}} \\
& =\left\|x_{n-1}-y_{n}\right\|+\operatorname{Ld}\left(x_{n}, T x_{n-1}\right)+\delta^{k_{n-1}} \\
& \leq\left\|x_{n-1}-y_{n}\right\|+L\left\|x_{n}, y_{n}\right\|+\delta^{k_{n-1}} \\
& =\left\|x_{n-1}-y_{n}\right\|+L\left\|x_{n-1}, y_{n}\right\| \\
& -L\left\|x_{n-1}, x_{n}\right\|+\delta^{k_{n-1}} \\
& =(1+L)\left\|x_{n-1}-y_{n}\right\|-L\left\|x_{n-1}, x_{n}\right\| \\
& +\delta^{k_{n-1}} \leq(1+L)\left\|y_{n-1}-y_{n}\right\|+\delta^{k_{n-1}} \\
& \leq(1+L) H\left(x_{n-2}, x_{n-1}\right)+(1+L) \delta^{k_{n-2}} \\
& +\delta^{k_{n-1}} \\
& \leq(1+L) \delta\left\|x_{n-2}-x_{n-1}\right\| \\
& +(1+L) L d\left(x_{n-1}, T x_{n-2}\right) \\
& +(1+L) \delta^{k_{n-2}}+\delta^{k_{n-1}} \\
& =(1+L) \delta\left\|x_{n-2}-x_{n-1}\right\|+(1+L) \delta^{k_{n-2}} \\
& +\delta^{k_{n-1}} \text {. }
\end{aligned}
$$


We denote $h=(1+L) \delta<1$, so

$$
\left\|x_{n}-x_{n+1}\right\| \leq h\left\|y_{n-2}-y_{n-1}\right\|+h \delta^{k_{n-3}}+\delta^{k_{n-1}} .
$$

Therefore, combining Cases 1, 2, and 3, we obtain

$$
\begin{aligned}
\left\|x_{n}-x_{n+1}\right\| \leq & h \max \left\{\left\|x_{n-1}-x_{n}\right\|,\left\|x_{n-2}-x_{n-1}\right\|\right\} \\
& +h \delta^{k_{n-3}}+\delta^{k_{n-1}} \\
\leq & h \max \left\{\left\|x_{n-1}-x_{n}\right\|,\left\|x_{n-2}-x_{n-1}\right\|\right\} \\
& +h^{k_{n-3}+1}+h^{k_{n-1}} \\
\leq & h \max \left\{\left\|x_{n-1}-x_{n}\right\|,\left\|x_{n-2}-x_{n-1}\right\|\right\} \\
& +h^{n-3}+h^{n-1}
\end{aligned}
$$

for all $n \geq 2$. By inductivity, it follows that, for any $n>1$,

$$
\begin{aligned}
\left\|x_{n}-x_{n+1}\right\| \leq & h^{n / 2} \max \left\{\left\|x_{0}-x_{1}\right\|,\left\|x_{1}-x_{2}\right\|\right\} \\
& +h^{(n-1) / 2} n .
\end{aligned}
$$

Now, for any $n>m$, we obtain

$$
\begin{aligned}
& \left\|x_{m}-x_{n}\right\| \leq\left\|x_{m}-x_{m+1}\right\|+\left\|x_{m+1}-x_{m+2}\right\|+\cdots \\
& +\left\|x_{n-1}-x_{n}\right\| \leq\left(h^{(m-1) / 2}+h^{m / 2}+\cdots+h^{(n-2) / 2}\right) \\
& \cdot \max \left\{\left\|x_{0}-x_{1}\right\|,\left\|x_{1}-x_{2}\right\|\right\}+h^{(m-1) / 2} m \\
& +h^{m / 2}(m+1)+\cdots++h^{(n-1) / 2} n .
\end{aligned}
$$

This implies that $\left\{x_{n}\right\}$ is a Cauchy sequence. Since $C$ is closed and $\left\{x_{n}\right\} \subset C$, there exists $x \in C$ such that $\lim _{n \rightarrow \infty} x_{n}=x$. Let $\left\{x_{n_{k}}\right\} \subset P$ be an infinite subsequence of $\left\{x_{n}\right\}$. Since $X$ has Property A, $\left(x_{n_{k}}, x\right) \in E(G)$ for all $k \in \mathbb{N}$. Then we have

$$
\begin{aligned}
d(x, T x) & \leq\left\|x-x_{n_{k}+1}\right\|+d\left(x_{n_{k}+1}, T x\right) \\
& =\left\|x-x_{n_{k}+1}\right\|+H\left(T x_{n_{k}}, T x\right) \\
& \leq\left\|x-x_{n_{k}+1}\right\|+\delta\left\|x_{n_{k}}-x\right\|+L d\left(x, T x_{n_{k}}\right) \\
& =(1+L)\left\|x-x_{n_{k}+1}\right\|+\delta\left\|x_{n_{k}}-x\right\| .
\end{aligned}
$$

Letting $k \rightarrow \infty$, we obtain

$$
d(x, T x)=0
$$

and hence $x \in T x$ : that is, $x$ is a fixed point of $T$. This completes the proof.

As a consequence of Theorem 5 , by putting $E(G)=C \times C$, we obtain the following corollary.

Corollary 6. Let $K$ be a nonempty closed subset of a Banach space $X$ and $T: K \rightarrow C B(X)$ be an almost contractive mapping with Rothe's boundary condition. Then T has a fixed point.
Remark 7. (i) In Theorem 5 , if we take $E(G)=X \times X$, we obtain Theorem 9 of Alghmdi et al. [4] in Banach spaces.

(ii) In Theorem 5, if we take $E(G)=X \times X$ and $T: K \rightarrow X$, we obtain the existence result which is similar to Berinde and Păcurar's result [5].

(iii) In Theorem 5, if we take $T: X \rightarrow X$ and $L=0$, we obtain the existence result which is similar to Jachymski's result [5] in Banach spaces.

(iv) In Theorem 5, if we take $E(G)=X \times X$ and $L=$ 0 , we obtain the existence result which is similar to Nadler's theorem [5] in Banach spaces.

Next, we give an example to illustrate Theorem 5.

Example 8. Let $X=\mathbb{R}$ and $K=[0, \infty)$ with the usual norm $\|x-y\|=|x-y|$ and $G=(V(G), E(G))$ be such that $V(G)=$ $K$,

$$
\begin{aligned}
& E(G) \\
& =\left\{\left(\frac{1}{2^{n}}, \frac{1}{2^{2 n+1}}\right),\left(\frac{1}{2^{n}}, 0\right),\left(\frac{1}{2^{2 n+1}}, \frac{1}{2^{2 n+2}}\right): n \geq 2\right\} \\
& \cup\left\{\left(\frac{1}{2}, 0\right),(0,0)\right\} .
\end{aligned}
$$

Notice that $K$ has Property A. Define a mapping $T: K \rightarrow$ $\mathrm{CB}(X)$ by

$T x$

$$
= \begin{cases}\{0\} & \text { if } x=0, \\ \left\{-\frac{1}{8}\right\} & \text { if } x=\frac{1}{2}, \\ \left\{\frac{1}{2^{2 k}}, \frac{1}{2^{2 k+1}}\right\} & \text { if } x=\frac{1}{2^{2 k+1}}, k \in \mathbb{N} \cup\{0\} \\ \left\{\frac{1}{2^{2 k+2}}, \frac{1}{2^{2 k+3}}\right\} & \text { if } x=\frac{1}{2^{2 k}}, k \in \mathbb{N} \cup\{0\} \backslash\left\{\frac{1}{2}\right\} .\end{cases}
$$

We see that the only $x \in K$ with $T x \notin K$ is $x=1 / 2$, and we see that $P_{T}(1 / 2)=\{0\}$ and $(1 / 2,0) \in E(G)$; hence, $P_{T}(x)$ is dominated by $x$. By direct computation, we can show that $T$ is $G$-almost contraction with $\delta=1 / 4$ and $L=2$. Moreover, we see that

$$
\begin{aligned}
T(\partial K) & =T(\{0,1\})=\{0,1\} \\
& \Longrightarrow T 0 \text { and } T 1 \text { are subset of } K,
\end{aligned}
$$

which implies $T$ satisfies Rothe's boundary condition. Choose $x_{0}=0 \in \partial C$, we see that $\left(x_{0}, T x_{0}\right)=(0,0) \in E(G)$. Therefore, all conditions of Theorem 5 are satisfied and we see that $F(T)=\{0\}$.

\section{Competing Interests}

The authors declare no competing interests.

\section{Acknowledgments}

The authors would like to thank the Thailand Research Fund under Project RTA5780007 and Chiang Mai University, 
Chiang Mai, Thailand, for the financial support. The first author was supported by Chiang Mai Rajabhat University.

\section{References}

[1] S. Banach, "Sur les oprations dans les ensembles abstraits et leur application aux quations intgrales," Fundamenta Mathematicae, vol. 3, pp. 133-181, 1922.

[2] J. Nadler, "Multi-valued contraction mappings," Pacific Journal of Mathematics, vol. 30, pp. 475-488, 1969.

[3] N. A. Assad, "A fixed point theorem for some non-self-mappings," Tamkang Journal of Mathematics, vol. 21, no. 4, pp. 387393, 1990.

[4] M. A. Alghamdi, V. Berinde, and N. Shahzad, "Fixed points of non-self almost contractions," Carpathian Journal of Mathematics, vol. 30, no. 1, pp. 7-14, 2014.

[5] V. Berinde and M. Păcurar, "Fixed point theorems for nonself single-valued almost contractions," Fixed Point Theory, vol. 14, no. 2, pp. 301-312, 2013.

[6] J. Jachymski, "The contraction principle for mappings on a metric space with a graph," Proceedings of the American Mathematical Society, vol. 136, no. 4, pp. 1359-1373, 2008.

[7] I. Beg and A. R. Butt, "Fixed point of set-valued graph contractive mappings," Journal of Inequalities and Applications, vol. 2013, article 252, 2013.

[8] F. Bojor, "Fixed point theorems for Reich type contractions on metric spaces with a graph," Nonlinear Analysis. Theory, Methods \& Applications, vol. 75, no. 9, pp. 3895-3901, 2012.

[9] M. R. Alfuraidan, "Fixed points of monotone nonexpansive mappings with a graph," Fixed Point Theory and Applications, vol. 2015, article 49, 2015.

[10] J. Tiammee and S. Suantai, "Coincidence point theorems for graph-preserving multi-valued mappings," Fixed Point Theory and Applications, vol. 2014, article 70, 2014.

[11] J. Tiammee, A. Kaewkhao, and S. Suantai, “On Browder's convergence theorem and Halpern iteration process for $G$-nonexpansive mappings in Hilbert spaces endowed with graphs," Fixed Point Theory and Applications, vol. 2015, article no. 187, 2015.

[12] N. Hussain, J. Ahmad, and A. Azam, "Generalized fixed point theorems for multi-valued $\alpha-\varphi$ contractive mappings," Journal of Inequalities and Applications, vol. 2014, p. 384, 2014.

[13] N. Hussain, J. Ahmad, and M. A. Kutbi, "Fixed point theorems for generalized Mizoguchi-Takahashi graphic contractions," Journal of Function Spaces, vol. 2016, Article ID 6514920, 7 pages, 2016.

[14] M. R. Alfuraidana, M. Bacharb, and M. A. Khamsi, "Almost monotone contractions on weighted graphs," The Journal of Nonlinear Science and Applications, vol. 9, pp. 5189-5195, 2016.

[15] R. P. Agarwal, D. O'Regan, and D. R. Sahu, Fixed Point Theory for Lipschitzian-Type Mappings with Applications, Springer, New York, NY, USA, 2009.

[16] C. Pang, R. Zhang, Q. Zhang, and J. Wang, "Dominating sets in directed graphs," Information Sciences, vol. 180, no. 19, pp. 36473652, 2010.

[17] J. Bang-Jensen and G. Gutin, Digraphs Theory, Algorithms and Applications, Springer Monographs in Mathematics, Springer, London, UK, 2007. 


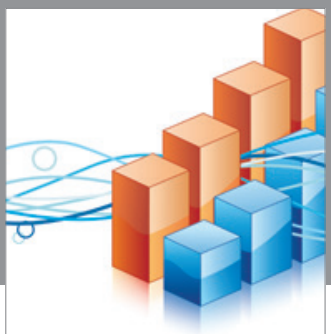

Advances in

Operations Research

vatem alat4

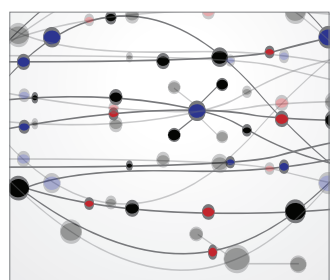

\section{The Scientific} World Journal
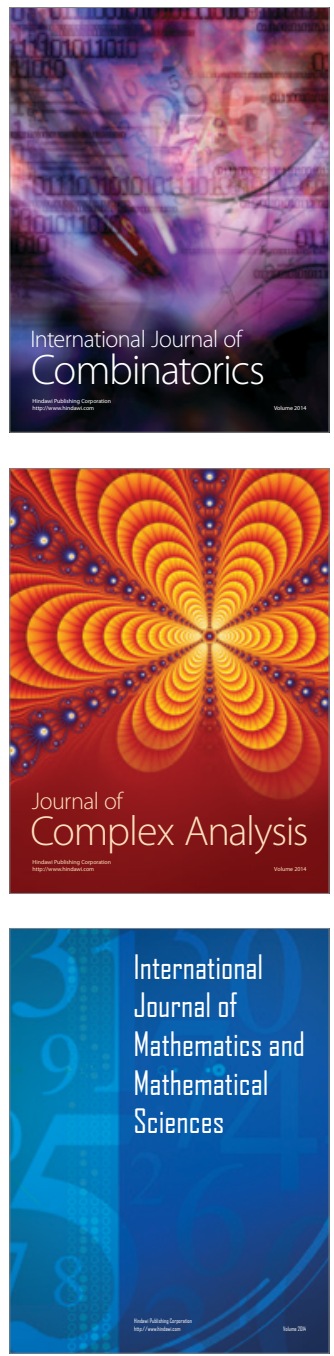
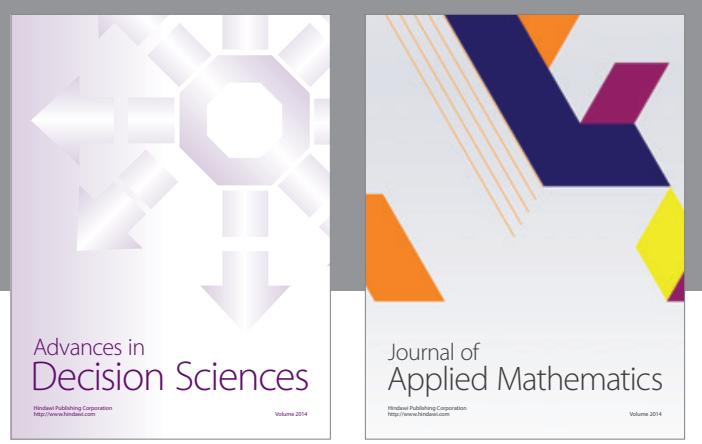

Algebra

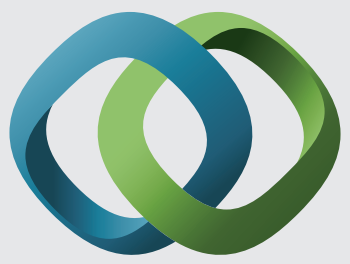

\section{Hindawi}

Submit your manuscripts at

https://www.hindawi.com
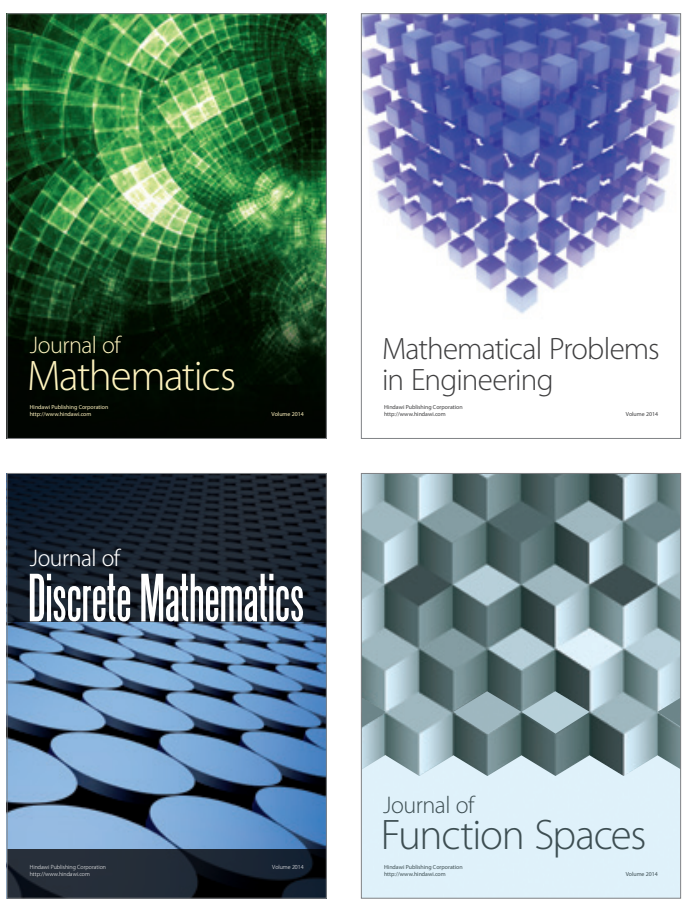

Mathematical Problems in Engineering
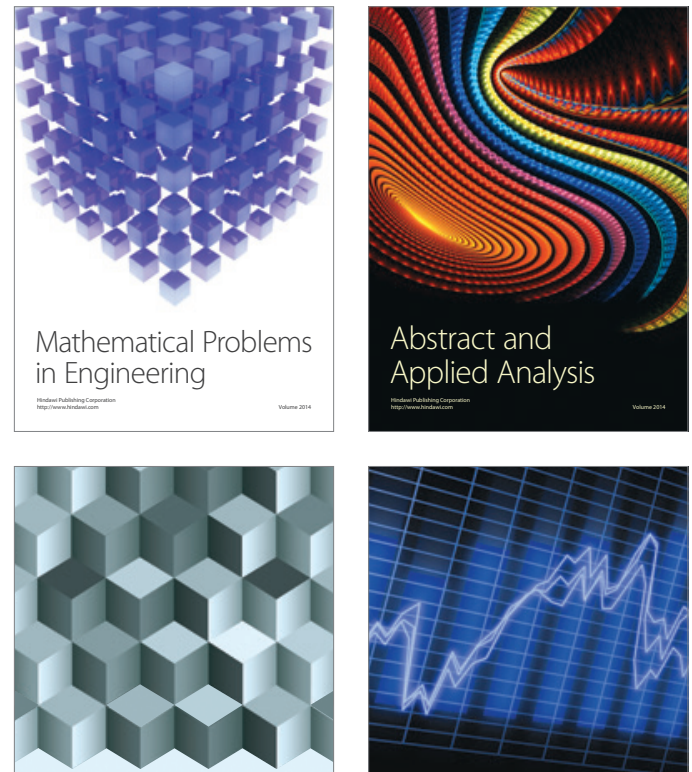

Journal of

Function Spaces

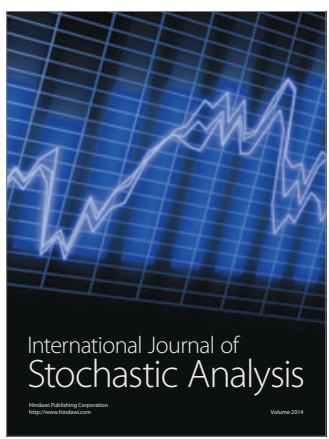

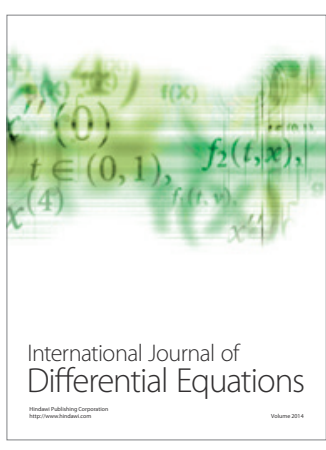
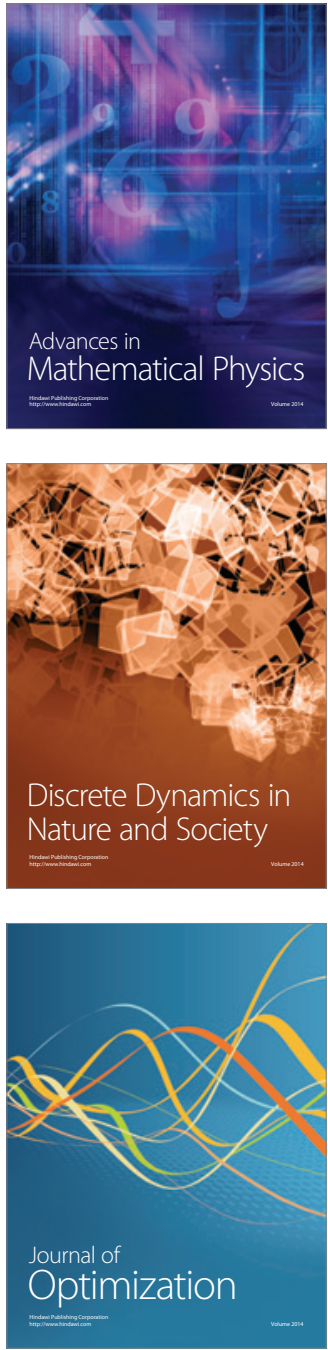